Research Article

\title{
Evaluation of Caries-Free Restorations Bonded with Various Adhesive Systems: In Vitro Study
}

\author{
Morakot Piemjai $($ D, Pareewan Chantarawej, and Nobuo Nakabayashi \\ Department of Prosthodontics, Faculty of Dentistry, Chulalongkorn University, Bangkok, Thailand \\ Correspondence should be addressed to Morakot Piemjai; tmorakot@chula.ac.th
}

Received 31 January 2020; Revised 15 May 2020; Accepted 23 May 2020; Published 22 July 2020

Academic Editor: Leonzio Fortunato

Copyright (C) 2020 Morakot Piemjai et al. This is an open access article distributed under the Creative Commons Attribution License, which permits unrestricted use, distribution, and reproduction in any medium, provided the original work is properly cited.

Purpose. Secondary caries originate from a leakage pathway where oral acids can penetrate faster and demineralize the tooth substrate deeper which can be visualized by dye penetration. The ability to prevent secondary caries by contemporary adhesive systems was evaluated in this study. Dye penetration distance through leakage and into the tooth substrate adjacent to Class V restorations after artificial caries exposure was compared. Materials and Methods. Previously frozen extracted human molars were used to prepare the Class V cavities at the CEJ on axial surfaces. All cavities were restored with either the resin-composite or amalgam with or without resin adhesives: dry bonding: Super-Bond D-Liner II Plus; moist bonding: AllBond 2; and self-etch bonding: AQ Bond and Clearfil Protect Bond. Two subgroups of Super-Bond D-Liner II Plus were immersed for 14 days at $37^{\circ} \mathrm{C}$ either in artificial saliva (negative control) or the artificial caries solution. The other groups were soaked in the artificial caries solution. The distance of dye penetration into the adjacent enamel, cementum/dentin, and tooth-resin interfaces was measured after immersion in $0.5 \%$ basic fuchsin dye for $24 \mathrm{~h}$. The tooth-resin interfacial layer was investigated using SEM. Results. No dye penetration into the tooth-resin interface was found in Super-Bond D-Liner II Plus and AQ Bond groups which demonstrated a constant hybrid layer after a chemical challenge. The leakage distance at the cementum/dentin-resin interface of All-Bond 2, Clearfil Protect Bond, and non-adhesive amalgam (positive control) groups was significantly higher than the distance of dye penetration into the adjacent demineralized root surface $(p<0.05)$. Conclusion. Caries associated with either amalgam or resin-composite restorations can be prevented using resin adhesives which can penetrate into the intact tooth substrate to form a stable hybrid layer. With caries-free restorations, tooth vitality may be conserved lifelong.

\section{Introduction}

Amalgam restorations have been used worldwide for more than 120 years because they are long lasting, low cost, and/or easy to manipulate. However, with the dark silver like color and the low levels of mercury vapor, they have been increasingly replaced with the tooth-colored resin-composite restorations. Hybridization of resin into the enamel or dentin creates a hybrid layer which provides the adhesion strength to the above cured resin adhesives [1]; therefore, with amalgam or resin-composite restorations coupled with this layer, it is not necessary to remove the sound tooth structure for mechanical retention or strength for long-term survival [2, 3]. This makes resin adhesives, which can provide a complete hybrid layer, one of the major contributors in conserving the tooth structure for life-long use.

In the last 40 years, dental adhesives have been developed from dry, wet or moist, to self-etch tooth conditioning to reduce clinical complications such as tooth hypersensitivity, secondary caries, pulpal infection, and/or restoration detachment. Many dentin-bonding adhesives such as a totaletch with either dry or moist techniques and self-etch systems have been introduced into the worldwide market to promote better retention and bond strength between the tooth-colored filling materials and the dentin substrate. Impermeable hybridized dentin prepared by penetrating a polymer network using 4-methacryloyloxyethyl trimellitate anhydride in methyl methacrylate initiated by the tri- $n$-butyl 
borane (4-META/MMA-TBB) resin into non-collagen collapsed dry bonding of demineralized dentin provides high tensile strength with cohesive failure occurring in resin and defect-free bonded specimens [4, 5]. This bonding technique has been clinically utilized since the 1980s. Tensile testing using mini-dumbbell specimens and a chemical challenge using $\mathrm{HCl}$ and $\mathrm{NaOCl}$ solutions have been shown to be effective in detecting defects such as remaining demineralized dentin, smears, and hybridized smear layer in the dentin-bonded specimens [5-7]. Very high microtensile bond strength in some wet or moist bonding techniques has been reported with mixed adhesive and cohesive failure; however, the quality of the hybrid layer was not well characterized except for nanoleakage and short-term degradation of the resin-dentin interfacial layer $[8,9]$. Phosphoric acid conditioning of the dentin and moist bonding must be carefully controlled so as to not introduce permeable [10] and hydrolysable [11] demineralized dentin into the restored dentin which may then induce a wall lesion [12]. Simplification of the bonding steps from three- or two-step etch and rinse to two- or one-step self-etch by combining the etchant, primer, and/or bonding ingredients is highly effective in eliminating technical sensitivity while allowing easy manipulation just like for amalgam fillings. However, countering adverse effects of smears and hybridized smears using a self-etching system on reliable bonding for a complete seal is needed to prevent a leakage pathway [13-15].

One of the commonest failures in restored teeth is due to secondary caries. Fluoride ion-releasing adhesive material was reported for better caries prevention [16]. Nevertheless, secondary caries is still the major cause of failure of fluoride-releasing glass ionomer fillings [17, 18]. Also, in clinical studies, the incidence of secondary caries was not significantly reduced by the fluoride release from restorative materials [19]. Secondary caries may have been developed from leakage between the restorations and the tooth [20]. Visualization of the basic fuchsin dye, which easily binds to acidic GAGs in the demineralized dentin and accurately marks artificial root caries and initial wall lesions in the leakage pathway, suggests that a complete leakage-free hybrid layer can block lactic acid which is believed to be involved in the initial cause of caries [12]. Therefore, the ability to prevent secondary caries and complete microsealing, using a variety of commercial bonding adhesives, is simply demonstrated using artificial caries simulation and dye detection. The study hypothesis was that secondary caries could be inhibited by adhesive systems that could provide a stable hybrid layer with no leakage.

The objective of this study was to compare the effectiveness in preventing secondary caries of commercial adhesive systems. The dye penetration distance around the Class $\mathrm{V}$ resin-composite or amalgam restorations either using dry (Super-Bond D-Liner II Plus), moist (All-Bond 2), or self-etch (AQ Bond and Clearfil Protect Bond) bonding adhesives after artificial caries exposure was measured. The characteristics of the tooth-resin interface for each adhesive was analyzed using SEM.

\section{Materials and Methods}

The vital human molars that required extraction with the patients' signed informed consent were collected and frozen for less than 6 months. Teeth without cracks or caries were selected to prepare Class V cavities on axial surfaces at the CEJ using diamond burs (204, Intensiv, Grancia, Switzerland) with a high-speed hand piece under water spray. The box-form cavities approximately $2 \mathrm{~mm}$ high, $3 \mathrm{~mm}$ wide, and $1.5 \mathrm{~mm}$ deep with the occlusal margin in the enamel and the cervical margin in the cementum were randomly divided into 6 groups. Amalgam (Dispersalloy, DENTSPLY International Inc., DE, USA) restorations without adhesives (Non) were prepared for a positive control group. Four different bonding agents: dry (Super-Bond D-Liner II Plus (Sup; Sun Medical, Shiga, Japan)), moist (All-Bond 2 (All; Bisco Inc., IL, USA)), and self-etch (AQ-Bond (AQ; Sun Medical, Shiga, Japan) and Clearfil Protect Bond (Cle; Kuraray Medical Inc., Okayama, Japan)) were used for the remaining groups. The manipulation of adhesives followed the recommendations of the manufacturers (Table 1). Amalgam was used to restore in the Super-Bond D-Liner II Plus group, while the resin-composite (Metafil, Sun Medical, Shiga, Japan) was used in the other groups. After light-cured for $60 \mathrm{~s}$ or self-curing for $10 \mathrm{~min}$, the resin-composite-restored margins were finished with fine diamond burs (4205, Intensiv, Grancia, Switzerland) with a high-speed hand piece, while fine white stone burs with a slow-speed hand piece were used to finish the amalgam-restored margins. Two subgroups of Super-Bond D-Liner II Plus were immersed for 14 days at $37^{\circ} \mathrm{C}$ either in artificial saliva (negative control) or $0.1 \mathrm{~mol}$ lactic acid in buffer solution (the artificial caries solution with a $\mathrm{pH}$ of 4.5) [12], while the other three groups: All-Bond 2, AQ-Bond, and Clearfil Protect Bond were soaked only in the artificial caries solution.

After cleaning and drying, all tooth surfaces were coated with two layers of nail varnish (Pias, Bangkok, Thailand), leaving the restoration and $1 \mathrm{~mm}$ above and below the enamel and cementum/dentin margins, respectively. All the samples were immersed in $0.5 \%$ basic fuchsin dye for $24 \mathrm{~h}$ prior to vertically sectioning through the middle of the cavities using a diamond disk and a micromotor hand piece to make two sections. The surface of each section was polished to be horizontally parallel using abrasive papers with the grit size $\# 400$ to $\# 2,000$. The distance of dye penetration into the adjacent enamel and cementum/dentin and the tooth-cured adhesive interface was measured using Image-Pro Plus software on a standardized image taken from a stereomicroscope attached to a digital camera (Nikon, Japan) at $\times 50, \times 100$, and $\times 200$. Sectioned specimens with a crack line that influenced the dye penetration were excluded. The distance data were statistically analyzed using one-way ANOVA and multiple comparisons tests of the SPSS program at $p<0.05$.

Four cavities of each bonding agents were prepared according to the method mentioned earlier to evaluate the tooth-resin interfacial layer. The sectioned specimens without epoxy embedding were sequentially abraded using the \#400, \#600, \#800, \#1,000, and \#2,000 grit size silicon 
TABLE 1: The composition and bonding technique of adhesive materials.

\begin{tabular}{|c|c|c|}
\hline Adhesive system & Composition & Bonding technique \\
\hline Self-etch & $\begin{array}{l}\text { Monomers: MMA, 4-META, UDMA, 2-hydroxyethyl } \\
\text { methacrylate, acetone, water }\end{array}$ & $\begin{array}{l}\text { Scrubbed with monomer-soaked sponge on tooth } \\
\text { surface for } 20 \mathrm{~s} \text {, air-dried } 5 \mathrm{~s} \text {, once more scrubbed, } \\
\text { air-dried } 10 \mathrm{~s} \text {, light-cured } 10 \mathrm{~s}\end{array}$ \\
\hline $\begin{array}{l}\text { AQ-Bond (Touch \& } \\
\text { Bond) }\end{array}$ & Sponge: polyurethane foam, $p$-TSNa & Bulk filled with resin-composite, light-cured $60 \mathrm{~s}$ \\
\hline Self-etch & $\begin{array}{c}\text { Primer: 10-MDP, } 12 \text { MDPB, HEMA, hydrophilic } \\
\text { dimethacrylates, water }\end{array}$ & $\begin{array}{l}\text { Applied primer for } 20 \mathrm{~s} \text {, air-dried } 5 \mathrm{~s} \text {, applied } \\
\text { monomers, air-dried } 5 \mathrm{~s} \text {, light-cured } 10 \mathrm{~s}\end{array}$ \\
\hline $\begin{array}{l}\text { Clearfil Protect Bond } \\
\text { (Clearfil SE Protect) }\end{array}$ & $\begin{array}{l}\text { Monomers: MDP, Bis-GMA, HEMA, hydrophobic } \\
\text { dimethacrylate, N, N-diethanol-p-toluidine, silanated } \\
\text { colloidal silica, surface-treated sodium fluoride }\end{array}$ & Bulk filled with resin-composite, light-cured $60 \mathrm{~s}$ \\
\hline Moist bonding & Etchant: $32 \% \mathrm{H}_{3} \mathrm{PO}_{4}$, water & $\begin{array}{c}\text { Applied etchant for } 15 \mathrm{~s} \text {, rinsed off } 15 \mathrm{~s} \text {, air-dried } 2 \mathrm{~s} \text {, } \\
\text { kept moist }\end{array}$ \\
\hline \multirow{2}{*}{ All-Bond 2} & Primer: $2 \%$ NTG-GMA, 16\% BPDM, acetone & $\begin{array}{l}\text { Mixed primer } 1: 1 \text { drop for } 3 \mathrm{~s}, 5 \text { coatings on tooth } \\
\text { surface, air-dried } 5 \mathrm{~s} \text {, light-cured } 20 \mathrm{~s}\end{array}$ \\
\hline & Bonding: bis-GMA, UDMA, HEMA & $\begin{array}{l}\text { Applied bonding agent and bulk filled with resin- } \\
\text { composite, light-cured } 60 \mathrm{~s}\end{array}$ \\
\hline \multirow{3}{*}{$\begin{array}{l}\text { Dry bonding } \\
\text { Super-Bond D-Liner II } \\
\text { PLUS (Amalgam Bond } \\
\text { Plus) }\end{array}$} & Etchant: $10 \%$ citric acid, $3 \% \mathrm{FeCl}_{2}(10-3)$, water & Applied etchant for $10 \mathrm{~s}$, rinsed off $10 \mathrm{~s}$, air-dried $10 \mathrm{~s}$ \\
\hline & $\begin{array}{l}\text { Monomers: 2, 2-bis[4-(methacryloxy polyethoxy) } \\
\text { phenyl]propane, HEMA, 4-META, MMA, TBB }\end{array}$ & $\begin{array}{l}\text { Mixed } 2 \text { drops of monomer: } 1 \text { drop TBB, applied on } \\
\text { tooth surface using brush dip technique, autocured }\end{array}$ \\
\hline & Powder: PMMA & Bulk filled with amalgam \\
\hline
\end{tabular}

carbide paper and finished with $0.05 \mu \mathrm{m}$ alumina under wet conditions. One piece of each specimen was soaked into $6 \mathrm{~mol} / \mathrm{L} \mathrm{HCl}$ for $30 \mathrm{~s}$, followed by $1 \% \mathrm{NaOCl}$ for $60 \mathrm{~min}$. The quality of the hybrid layer was investigated under SEM.

\section{Results}

Dye penetration distances (mean $\pm \mathrm{SD}$ ) through leakage and into the tooth substrate adjacent to Class $\mathrm{V}$ restorations for all groups are shown in Table 2 . A leakage-free tooth-resin interface at the enamel and cementum/dentin margins was found in restorations coupled with Super-Bond D-Liner II Plus for both subgroups that were soaked in artificial saliva (negative control) and a lactic acid buffer and AQ-Bond specimens (Figures 1 and 2). Specimens in All-Bond 2, Clearfil Protect Bond, and nonadhesive amalgam (positive control) showed leakage both at the enamel- and cementum/dentin-resin interfaces (Figure 3).

No dye penetration into the adjacent enamel and cementum/dentin surfaces was found in all specimens soaked in artificial saliva (Sup, negative control), while specimens in all groups after artificial caries exposure showed dye penetration into the adjacent root surfaces with an average distance of $0.175 \pm 0.039 \mathrm{~mm} \quad(n=48)$. One-way ANOVA found no significant difference in the distance of dye penetration into the adjacent cementum/ dentin and leakage at the enamel- and cementum/dentinresin interface among groups at $p<0.05$. Pair- $t$ test $(p<0.05)$ revealed significantly higher distances of leakage into the cementum/dentin-resin interface than that of the enamel-resin interface and dye penetration into the adjacent cementum/dentin in all leakage groups. No dye penetrated into the adjacent enamel after caries exposure for 14 days.

The consistent thickness of 3-4 $\mu \mathrm{m}$ hybridized layer in Super-Bond D-Liner II Plus and a thin layer of approximately $1 \mu \mathrm{m}$ in AQ-Bond groups was demonstrated in both polished and chemically challenged specimens (Figures 4 and 5). A detached and degraded interfacial layer in AllBond 2 specimens after soaking in $\mathrm{HCl}$ and $\mathrm{NaOCl}$ was observed (Figure 6). The interfacial layer after chemical immersion of the Clearfil specimens was not consistent and degraded (Figure 7).

\section{Discussion}

For many decades, microleakage as a critical component for initiation of a caries lesion under restorations has been reported [21, 22]. When a complete hybrid layer with a leakage-free interface was formed, there was no remaining demineralized tooth substrate or smear layer for dye or lactic acid to penetrate through $[12,14,23]$. The study results showed that amalgam restorations coupled with Super-Bond D-Liner II Plus provided the leakage-free enamel- and dentin-resin interfaces when soaked in artificial saliva and artificial caries solution (Figures 1 and 2(a)). This suggests that Super-Bond D-Liner II Plus using a $10 \mathrm{~s}$ etching period of $10 \%$ citric acid and $3 \%$ ferric chloride (10-3) conditioner, rinsed off and then air-dried for $10 \mathrm{~s}$ could prepare a tissue substrate permeable for HEMA and 4-META/MMA-TBB monomers which entirely impregnated and then polymerized to form an impermeable hybrid layer which resisted lactic acid penetration, the cause of secondary caries. A 
TABLE 2: The distance of dye penetration into the adjacent tooth surface and the leakage at the tooth-resin interface for all groups (mean \pm SD in $\mathrm{mm}$ ).

\begin{tabular}{|c|c|c|c|c|}
\hline \multirow{2}{*}{ Bonding adhesives $(n)$} & \multicolumn{2}{|c|}{ Adjacent tooth surface } & \multicolumn{2}{|c|}{ Leakage at tooth-resin interface } \\
\hline & Enamel & Cementum/dentin & Enamel & Cementum/dentin \\
\hline Sup in artificial saliva (10) & 0 & 0 & 0 & 0 \\
\hline Sup in lactic acid buffer (10) & 0 & $0.185 \pm 0.045^{-}$ & 0 & 0 \\
\hline AQ in lactic acid buffer (10) & 0 & $0.153 \pm 0.030^{-}$ & 0 & 0 \\
\hline All in lactic acid buffer (10) & 0 & $0.185 \pm 0.032^{-,+}$ & $0.181 \pm 0.121^{\mathrm{a}}$ & $0.713 \pm 0.929^{\mathrm{b},+}$ \\
\hline Cle in lactic acid buffer (10) & 0 & $0.189 \pm 0.036^{-,+}$ & $0.061 \pm 0.117^{\mathrm{a}}$ & $0.840 \pm 0.894^{\mathrm{b},+}$ \\
\hline Non in lactic acid buffer (8) & 0 & $0.156 \pm 0.044^{-,+}$ & $0.342 \pm 0.339^{\mathrm{a}}$ & $0.558 \pm 0.222^{\mathrm{b},+}$ \\
\hline
\end{tabular}

$0=$ no dye penetration or no leakage. ${ }^{-}$No significant difference between groups $(p>0.05) .{ }^{+}$Significant difference between groups in the same row $(p<0.05)$.

${ }^{\mathrm{a}, \mathrm{b}}$ Significant difference between groups with different superscripts in the same row and colume $(p<0.05)$.

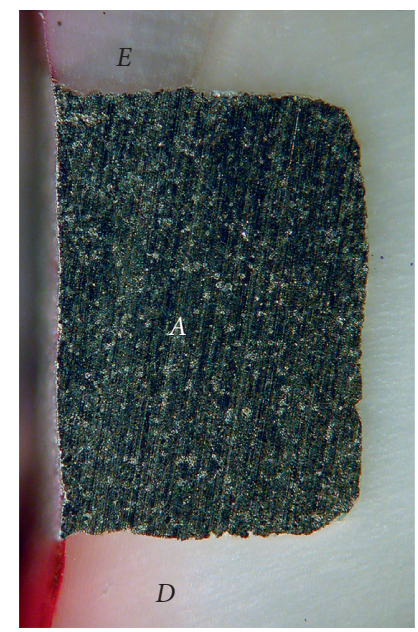

Figure 1: Leakage-free margin of amalgam bonded with Super-Bond D-Liner II Plus soaked in the artificial saliva, a negative control (original $\times 50, E=$ enamel, $D=$ dentin, and $A=$ amalgam).

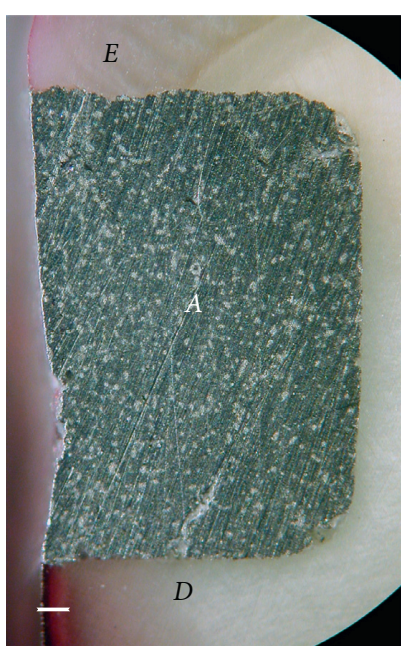

(a)

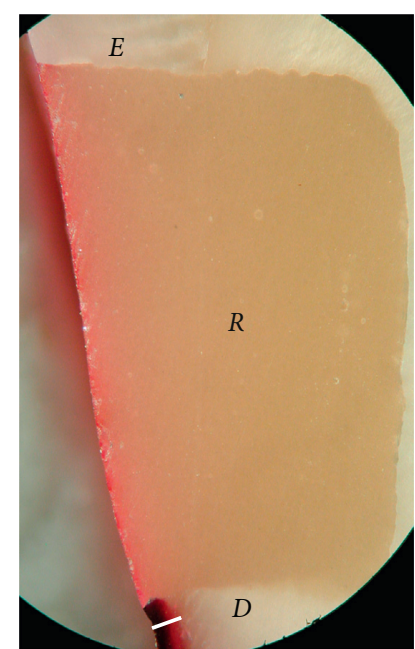

(b)

Figure 2: No dye penetration into the enamel- and cementum/dentin-resin interface and the adjacent enamel after artificial caries exposure: (a) amalgam bonded with Super-Bond D-Liner II Plus and (b) resin composite bonded with AQ-Bond (original $\times 50, E=$ enamel, $A=$ amalgam, $D=$ dentin, $R=$ resin composite, and a white line=dye penetration into the adjacent cementum/dentin). 


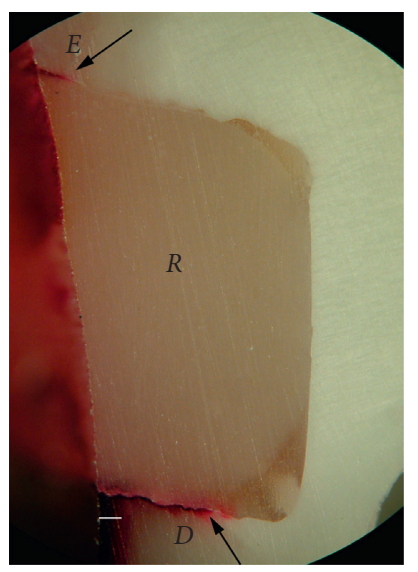

(a)

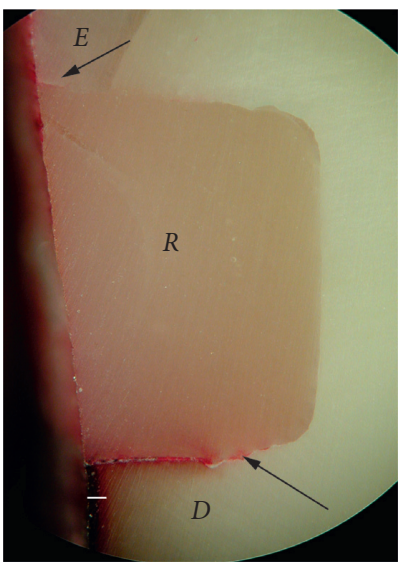

(b)

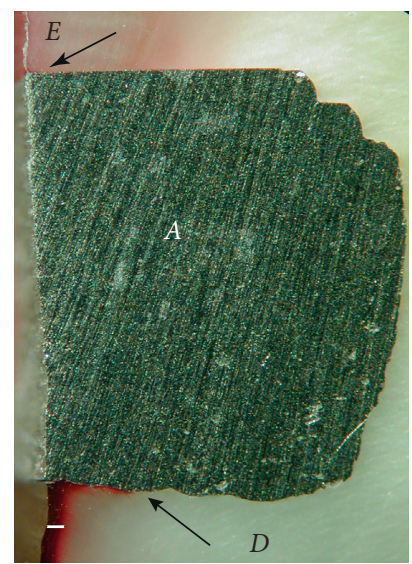

(c)

Figure 3: Dye penetration into leakage at the tooth-resin interface (arrowed) after artificial caries exposure: (a) All-Bond 2, (b) Clearfil Protect Bond, and (c) non-adhesive amalgam, a positive control (original $\times 50, E=$ enamel, $A=$ amalgam, $D=$ dentin, $R=$ resin-composite, and a white line $=$ dye penetration into the adjacent cementum/dentin).

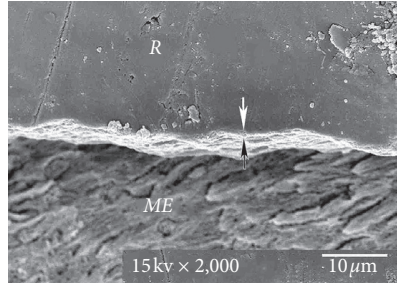

(a)

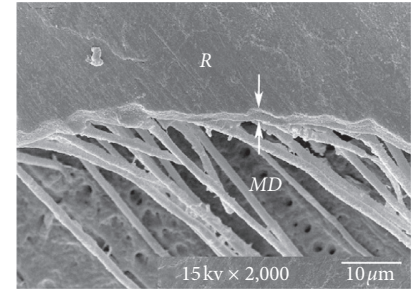

(b)

Figure 4: SEM micrograph of Super-Bond D-liner II Plus restored amalgam after chemical challenge, demonstrating the consistent and continuous thickness of the hybrid layer $(\approx 3-4 \mu \mathrm{m}$, arrowed) in the enamel (a) and dentin (b) (original $\times 2,000, M E=$ modified enamel, $M D=$ modified dentin, and $R=$ resin).

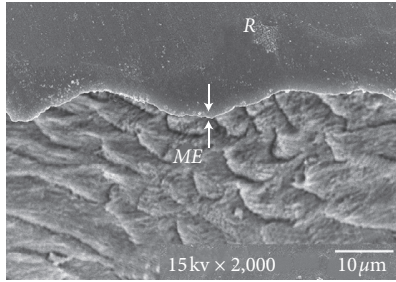

(a)

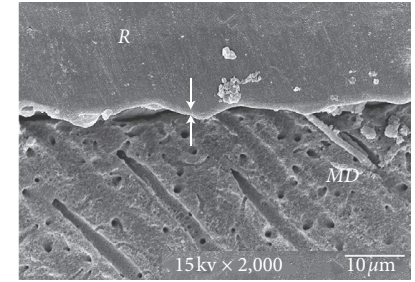

(b)

FIgURE 5: SEM micrograph of the AQ-Bond-restored resin composite after chemical challenge, demonstrating the consistent and continuous thickness of the hybrid layer $(\approx 1-2 \mu \mathrm{m}$, arrowed) in the enamel (a) and dentin (b) (original $\times 2,000, M E=$ modified enamel, $M D=$ modified dentin, and $R=$ resin).

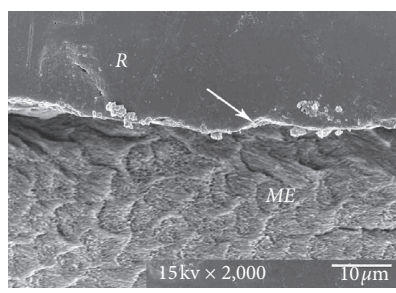

(a)

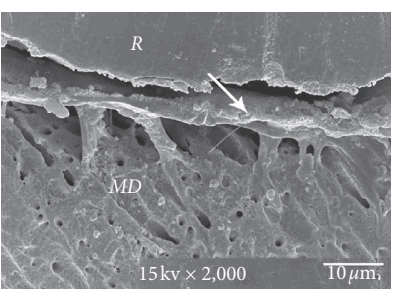

(b)

Figure 6: SEM micrograph of All-Bond 2-restored resin-composite after chemical challenge, demonstrating the detached and degraded interfacial layer (arrowed) in the enamel (a) and dentin (b) (original $\times 2,000, M E=$ modified enamel, $M D=$ modified dentin, and $R=$ resin). 


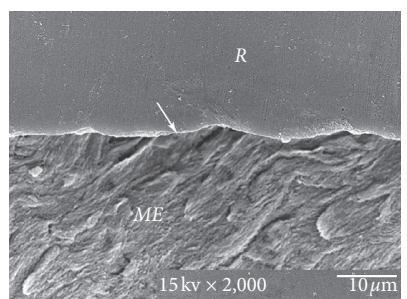

(a)

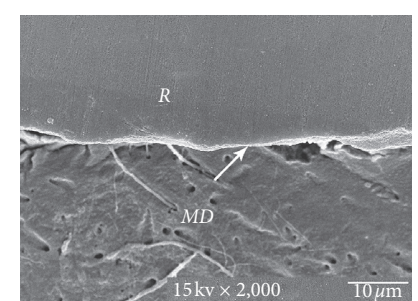

(b)

Figure 7: SEM micrograph of Clearfil Protect Bond-restored resin composite after chemical challenge, demonstrating the thin and degraded interfacial layer (arrowed) in the enamel (a) and dentin (b) (original $\times 2,000, M E=$ modified enamel, $M D=$ modified dentin, and $R=$ resin).

consistent thickness of 3-4 $\mu \mathrm{m}$ hybrid layer after chemical challenge suggests that the high resin content could entirely protect and seal the tissue substrate (Figure 4). Encapsulated hydroxyapatite not demineralized by $\mathrm{HCl}$ in the hybridized dentin confirms that complete hybridization can be achieved in vital human teeth [24]. This assumes that amalgambonded and tooth-sealed restorations using this dry bonding system can prevent secondary caries formation in the oral cavity. This complete hybrid layer combined with resincomposite restoration also shows the ability to prevent initial wall lesions [12].

Resin-composite bonded with AQ-Bond could inhibit the marginal leakage at the tooth-resin interface after soaking in the lactic acid buffer solution (Figure 2(b)). AQBond, the self-etch bonding agent, provided leakage-free tooth-resin interfaces by using monomer-soaked sponge scrubbing on the tooth surface for removal of a swollen smear layer, thus minimizing the adverse effect of a weak hybridized smear layer under the restoration $[13,14]$. With two times scrubbing to remove all the smear layers, AQbond could effectively penetrate into the intact tooth substrate to form a high resin content 1-2 $\mu \mathrm{m}$ hybrid layer (Figure 5), which could resist the penetration of the lactic acid buffer solution as well as the chemical challenge shown in this study.

The leakage of All-Bond 2, Clearfil, and non-adhesive amalgam specimens (Figure 3(a)-3(c), respectively) suggested a remaining of defect into which dye and lactic acid can penetrate $[10,14,25]$. All-Bond 2 using a phosphoric acid conditioner to remove the smear layer as same as to demineralize the underneath tooth substrate and kept moist could not reliably provide complete infiltration of monomers into the demineralized substrate as confirmed by the degraded interfacial layer after chemical challenge (Figure 6). The porous demineralized layer provided a pathway for the basic dye $[10,14,23]$ and hence for the lactic acid to penetrate [12]. The very thin and degraded interfacial layer after chemical challenge of Clearfil Protect Bond (Figure 7), the self-etch adhesive, implied that bonding monomers penetrated through the smear layer to form a hybridized smear layer was quite low; thus, smears remained and provided a leakage pathway as occurred in non-adhesive amalgam specimens. Fluoride-releasing properties in this self-etch adhesive has no influence to protect the tooth from secondary caries.
The significantly higher distance of leakage at the toothresin interface than that of dye penetration into the adjacent tooth surface demonstrated that lactic acid could diffuse into leakage pathways, i.e., smear layer, gap, or demineralized tooth substrate (tooth-cured adhesive interphase after phosphoric acid etching), faster than to the normal adjacent tooth surface (Table 2, Figure 3). The impermeable hybridized dentin with a leakage-free interface prepared by Super-Bond D-Liner II Plus or AQ-Bond could resist demineralization with lactic acid better than that to the adjacent normal root surface (Figure 2). This suggests that caries associated with restorations which initially occurs at the leakage pathway can be inhibited by the stable hybrid layer with the leakage-free tooth-resin interface.

\section{Conclusions}

Complete infiltration of resin into either air-dried, noncollapsed, 10-3 demineralized tooth substrate, or smear removal intact tooth surface provides the hybridized layer and tags that could resist the chemical challenge and lactic acid penetration better than that of the normal enamel and dentin. Tooth-colored restorations combined with this leakage-free hybrid layer are more reliable to protect the tooth from secondary caries than the non-adhesive amalgam and leaked resin-composite fillings. Without secondary caries, restored teeth may be maintained for life-long function and esthetics.

\section{Data Availability}

Raw data can be requested from the corresponding author.

\section{Conflicts of Interest}

The authors do not have any financial interest in the companies whose materials are included in this article.

\section{Acknowledgments}

The authors would like to express their appreciation to the Graduate School of Chulalongkorn University for the research funding and Associate Professor John Harcourt, the University of Melbourne, and the former editor of Australian Dental Journal, for the editorial suggestions. 


\section{References}

[1] N. Nakabayashi and D. H. Pashley, "Characterization of the hybrid layer," in Hybridization of Dental Hard Tissues, pp. 63-83, Quintessence, Tokyo, Japan, 1998.

[2] J. C. Setcos, M. Staninec, and N. H. F. Wilson, "The development of resin-bonding for amalgam restorations," British Dental Journal, vol. 186, no. 7, pp. 328-332, 1999.

[3] M. Piemjai, M. Özcan, F. Garcia-Godoy, and N. Nakabayashi, "A 10-year clinical evaluation of resin-bonded fixed dental prostheses on non-prepared teeth," European Journal of Prosthodontics and Restorative Dentistry, vol. 24, pp. 63-70, 2016.

[4] N. Nakabayashi, "Contribution of polymer chemistry to dentistry: development of an impermeable interpenetrating polymer network to protect teeth from acid demineralization," Polymer International, vol. 57, no. 2, pp. 159-162, 2008.

[5] N. Nakabayashi, A. Watanabe, and T. Arao, "A tensile test to facilitate identification of defects in dentine bonded specimens," Journal of Dentistry, vol. 26, no. 4, pp. 379-385, 1998.

[6] M. Piemjai and N. Nakabayashi, "Direct tensile strength and characteristics of dentin restored with all-ceramic, resincomposite and cast metal prostheses cemented with resin adhesives," BioMed Research International, 2015.

[7] M. Piemjai and N. Nakabayashi, "Effect of dentin conditioners on wet bonding of 4-META/MMA-TBB resin," The Journal of Adhesive Dentistry, vol. 3, no. 4, pp. 325-331, 2001.

[8] M. Hashimoto, H. Ohno, M. Kaga, K. Endo, H. Sano, and H. Oguchi, "In vivo degradation of resin-dentin bonds in humans over 1 to 3 years," Journal of Dental Research, vol. 79, no. 6, pp. 1385-1391, 2000.

[9] A. P. Manso, L. Marquezini, S. M. A. Silva, D. H. Pashley, F. R. Tay, and R. M. Carvalho, "Stability of wet versus dry bonding with different solvent-based adhesives," Dental Materials, vol. 24, no. 4, pp. 476-482, 2008.

[10] P. Spencer, Y. Wang, and B. Bohaty, "Interfacial chemistry of moisture-aged Class II composite restorations," Journal of Biomedical Materials Research Part B: Applied Biomaterials, vol. 77B, no. 2, pp. 234-240, 2006.

[11] M. Kiyomura, "Bonding strength to bovine dentin with 4META/MMA-TBB resin - long term stability and influence of water," Journal of the Japanese Society for Dental Materials, vol. 6, pp. 860-872, 1987.

[12] M. Piemjai, P. Chantarawej, N. Nakabayashi, and F. GarciaGodoy, "Prognosis test by visualization of demineralized dentin under restorations to prevent initial wall-lesions initiated by lactic acid," American Journal of Dentistry, vol. 30, pp. 119-124, 2017.

[13] H. Koibuchi, N. Yasuda, and N. Nakabayashi, "Bonding to dentin with a self-etching primer: the effect of smear layers," Dental Materials, vol. 17, no. 2, pp. 122-126, 2001.

[14] M. Piemjai, O. Waleepitackdej, F. García-Godoy, and N. Nakabayashi, "Dentin protection by a primer-less adhesive technique," American Journal of Dentistry, vol. 24, no. 5, pp. 284-288, 2011.

[15] R. Pinna, P. Usai, E. Filigheddu, F. Garcia-Godoy, and E. Milia, "The role of adhesive materials and oral biofilm in the failure of adhesive resin restorations," American Journal of Dentistry, vol. 30, no. 5, pp. 285-292, 2017.

[16] R. Walter, W. R. Duarte, P. N. Pereira, E. J. Swift Jr., H. O. Heymann, and R. R. Arnold, "Effect of resin adhesive systems on root caries formation in vitro," Quintessence International (Berlin, Germany: 1985), vol. 39, no. 1, pp. 33-37, 2008.
[17] F. J. Burke, S. W. Cheung, I. A. Mjör, and N. H. Wilson, "Restoration longevity and analysis of reasons for the placement and replacement of restorations provided by vocational dental practitioners and their trainers in the United Kingdom," Quintessence International, vol. 30, no. 4, pp. 234-242, 1999.

[18] I. A. Mjör, "The reasons for replacement and the age of failed restorations in general dental practice," Acta Odontologica Scandinavica, vol. 55, no. 1, pp. 58-63, 1997.

[19] A. Wiegand, W. Buchalla, and T. Attin, "Review on fluoridereleasing restorative materials-fluoride release and uptake characteristics, antibacterial activity and influence on caries formation," Dental Materials, vol. 23, no. 3, pp. 343-362, 2007.

[20] E. Hals, H. Andreassen, and T. Bie, "Histopathology of natural caries around silver amalgam fillings," Caries Research, vol. 8, no. 4 , pp. $343-358,1974$.

[21] E. A. Kidd, F. Toffenetti, and I. A. Mjör, "Secondary caries," International Dental Journal, vol. 42, no. 3, pp. 127-138, 1992.

[22] M. Fontana and C. González-Cabezas, "Secondary caries and restoration replacement: an unresolved problem," Compendium of Continuing Education in Dentistry, vol. 21, no. 1, pp. 15-30, 2000.

[23] M. Piemjai, A. Watanabe, Y. Iwasaki, and N. Nakabayashi, "Effect of remaining demineralised dentine on dental microleakage accessed by a dye penetration: how to inhibit microleakage?" Journal of Dentistry, vol. 32, no. 6, pp. 495501, 2004.

[24] N. Nakabayashi, M. Ashizawa, and M. Nakamura, "Identification of a resin-dentin hybrid layer in vital human dentin created in vivo: durable bonding to vital dentin," Quintessence International, vol. 23, no. 2, pp. 135-141, 1992.

[25] B. Van Meerbeek, S. Inokoshi, M. Braem, P. Lambrechts, and G. Vanherle, "Morphological aspects of the resin-dentin interdiffusion zone with different dentin adhesive systems," Journal of Dental Research, vol. 71, no. 8, pp. 1530-1540, 1992. 